\title{
Plutonium-238 Alpha Particle Radiation
}

National Cancer Institute

\section{Source}

National Cancer Institute. Plutonium-238 Alpha Particle Radiation. NCI Thesaurus. Code C129642.

Alpha rays produced by the decay of plutonium-238. 